\title{
Growth of Pt-Ni Nanoparticles of Different Composition using Electrodeposition and Characterization of Their Magnetic Properties
}

\author{
M. KoŽejováa ${ }^{a}$, D. HložnÁ ${ }^{a, *}$, Y. Hua Liu ${ }^{b}$, K. RÁCZOvá ${ }^{a}$, E. ČižMÁR ${ }^{a}$, M. OrendáČ $^{a}$ \\ AND V. KOMANICKÝa \\ ${ }^{a}$ Institute of Physics, Faculty of Sciences, P.J. Safarik University, Park Angelinum 9, 04154 Košice, Slovakia \\ ${ }^{b}$ Materials Science Division, Argonne National Laboratory, Argonne, Illinois 60439, USA
}

\begin{abstract}
We prepared $\mathrm{Pt}_{3} \mathrm{Ni}$ and $\mathrm{PtNi}_{3}$ nanoparticles of various sizes on conductive and atomically smooth highly oriented pyrolytic graphite surfaces using potentiostatic electrodeposition. We can control the size of electrodeposited nanoparticles and their density on the surface by changing the deposition time. The morphology of nanoparticles was determined by scanning electron microscopy. $\mathrm{PtNi}_{3}$ particles have spherical shape, while $\mathrm{Pt}_{3} \mathrm{Ni}$ particles have more irregular shape. Composition of particles was confirmed by energy dispersive spectroscopy. We have measured magnetic properties of both systems with $100 \mathrm{~s}$ preparation time, superparamagnetic behavior was observed in $\mathrm{PtNi}_{3}$ nanoparticles with blocking temperature $T_{B}=225 \mathrm{~K}$.
\end{abstract}

DOI: 10.12693/APhysPolA.131.839

PACS/topics: 75.75.+a, 75.75.Fk, 82.45.Qr, 68.37.Hk

\section{Introduction}

Interest in nanotechnology and nanoparticle science has enhanced internationally over the past 20 years. Typical size of magnetic nanoparticles is in the range from 1 to $100 \mathrm{~nm}$. These length scales provide their unique properties. Magnetic nanoparticles have a wide range of various applications. These applications use magnetic nanoparticles in a variety of forms, e.g. in solution as ferrofluids for audio speakers, as particle arrays in magnetic storage media [1], as surface, functionalized particles for biosensing applications [2], as powder compacts for power generation, conditioning and conversion, as contrasting agents in magnetic resonance imaging, in medical applications including magnetic targeted drug delivery, and alternatives to radioactive materials as tracers. Magnetic nanoparticles also provide an attractive alternative to conventional bulk magnetocaloric effect materials [3]. Electrodeposition is a simple, reproducible, and scalable approach for producing of thin films. The alloy composition is a monotonic function of deposition potential, with chemically homogeneous films being obtained by potentiostatic deposition at room temperature. Given a suitable conductive support, thin alloy catalyst films can be synthesized in a matter of seconds to minutes [4]. We have investigated this preparation technique to produce $\mathrm{Pt}-\mathrm{Ni}$ nanoparticles with different composition.

\section{Experimental methods}

Two types of $\mathrm{Pt}-\mathrm{Ni}$ alloy nanoparticles with different composition were prepared using electrodeposition

\footnotetext{
* corresponding author; e-mail: dominika.hlozna@student.upjs.sk
}

technique under potentiostatic conditions. The composition of $\mathrm{Pt}_{100-x} \mathrm{Ni}_{x}$ alloy was controlled by the potential applied during deposition to obtain particles with chemical composition $\mathrm{Pt}_{3} \mathrm{Ni}$ and $\mathrm{PtNi}_{3}$ (Fig. 1). $\mathrm{Pt}_{3} \mathrm{Ni}$ nanoparticles were electrodeposited at $-0.300 \mathrm{~V}$ and $\mathrm{PtNi}_{3}$ nanoparticles at $-0.600 \mathrm{~V}$ versus a saturated calomel electrode (SCE) on highly oriented pyrolytic graphite (HOPG). Deposition time of $100 \mathrm{~s}$ was used. Nanoparticles were grown from solution consisting of $0.003 \mathrm{~mol} / \mathrm{l}$ $\mathrm{K}_{2} \mathrm{PtCl}_{4}, 0.1 \mathrm{~mol} / 1 \mathrm{NiCl}_{2}$, and $0.5 \mathrm{~mol} / \mathrm{l} \mathrm{NaCl}$ with $\mathrm{pH}$ adjusted to 2.5 by addition of $\mathrm{HCl}$ and/or $\mathrm{NaOH}$. All solutions were prepared using ultrapure deionized water with electrical conductivity $18 \mathrm{M} \Omega \mathrm{cm}$. The electroplating cell consisted of closed glass beaker containing $50 \mathrm{ml}$ of the plating solution. We used $\mathrm{Ag} / \mathrm{AgCl}$ reference electrode $(\mathrm{RE})$, platinum wire as a counter electrode $(\mathrm{CE})$ and HOPG substrate connected to a platinum wire using a carbon paste as a working electrode (WE) (see Fig. 2).

In order to reduce the influence of surface contaminants, the top layer of HOPG was peeled off before each experiment using plastic tape. $\mathrm{Pt}-\mathrm{Ni}$ nanoparticles were electrodeposited by immersion of the WE into electrolyte at controlled potential. Growth of nanoparticles was terminated by removing WE from plating solution after predetermined time followed by rinsing the deposit with ultrapure deionized water. Performing the rinsing step promptly helped to minimize galvanic displacement of deposited $\mathrm{Ni}$ component by residual $\mathrm{Pt}^{2+}$ in the hanging meniscus.

Magnetic properties of selected nanoparticles were studied using a Quantum Design SQUID magnetometer in the temperature range from $5 \mathrm{~K}$ to $300 \mathrm{~K}$. The sample with area of $5 \times 5 \mathrm{~mm}^{2}$ was held in the plastic straw and the magnetic moment was measured with the magnetic field of 50 Oe applied parallel to the deposition surface along one of $5 \mathrm{~mm}$ sides. 


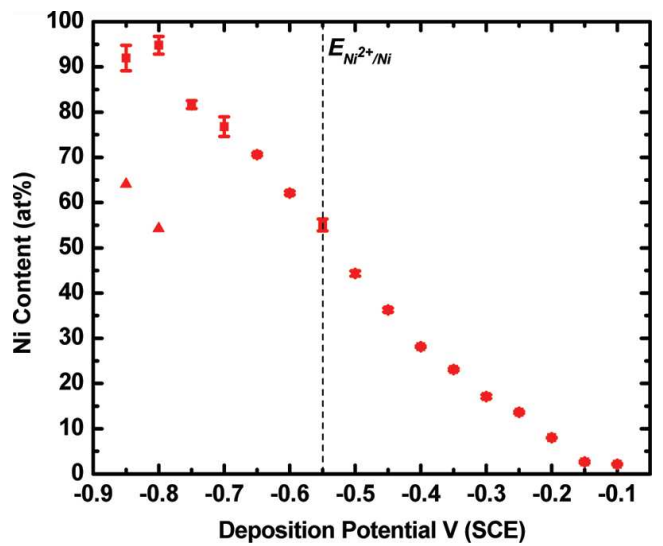

Fig. 1. Potential dependence of the composition of the electrodeposited $\mathrm{Pt}_{100-x} \mathrm{Ni}_{x}$ alloy films. Reprinted with permission from [4]. Copyright (2016) by American Chemical Society.

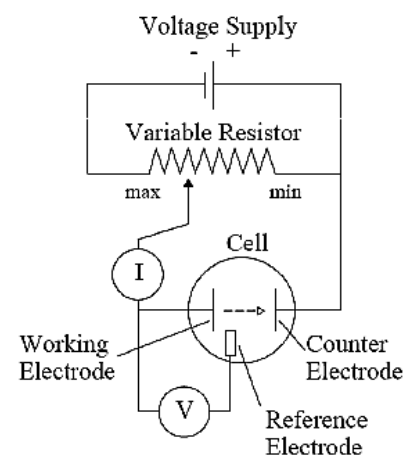

(a)

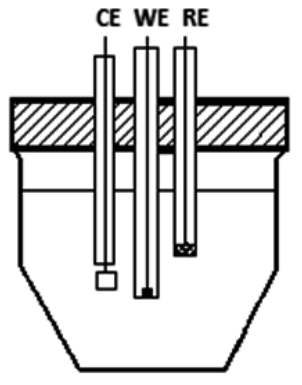

(b)
Fig. 2. Schematic representation of: (a) electrical circuit of a typical three-electrode cell in potentiostat, (b) experimental setup for the three-electrode cell.

\section{Results and discussion}

$\mathrm{Pt}_{3} \mathrm{Ni}$ and $\mathrm{PtNi}_{3}$ nanoparticles were characterized by scanning electron microscopy (SEM) and energy dispersive spectroscopy (EDS). The morphology of $\mathrm{Pt}-\mathrm{Ni}$ nanoparticles grown for $100 \mathrm{~s}$ at different potentials was examined (see Fig. 3 and Fig. 4). As one can see, $\mathrm{Pt}_{3} \mathrm{Ni}$ nanoparticles have irregular thorn-like shape with average size approximately $164 \mathrm{~nm}$ and wide particle size distribution (Fig. 5), while $\mathrm{PtNi}_{3}$ nanoparticles have spherical shape with diameter of around $133 \mathrm{~nm}$ with narrow particle size distribution (Fig. 6).

Composition of prepared nanoparticles was characterized by EDS and experimental results showed good agreement with the required chemical composition of $\mathrm{Pt}_{3} \mathrm{Ni}$ and $\mathrm{PtNi}_{3}$ nanoparticles.

Magnetic measurements were performed to probe possible particle size effect in nanoparticles grown for $100 \mathrm{~s}$. The temperature dependence of magnetic moment of both $\mathrm{Pt}_{3} \mathrm{Ni}$ and $\mathrm{PtNi}_{3}$ nanoparticles on HOPG measured in zero-field cooled (ZFC) and field-cooled (FC) mode is shown in Fig. 7. For comparison, the magnetic moment of pure HOPG substrate was also measured. Only a small diamagnetic contribution from $\mathrm{Pt}_{3} \mathrm{Ni}$ nanoparticles was observed in addition to magnetic moment of HOPG substrate. This was expected since bulk $\mathrm{Pt}_{3} \mathrm{Ni}$ alloys have no net magnetic moment in comparison to $\mathrm{PtNi}_{3}$ [5]. It should be noted that a small difference between $\mathrm{ZFC}$ and $\mathrm{FC}$ data measured on $\mathrm{HOPG}$ (and $\mathrm{Pt}_{3} \mathrm{Ni}$ nanoparticles on HOPG) is an evidence of already well-known defectinduced ferromagnetism observed in several carbon-based materials [6].

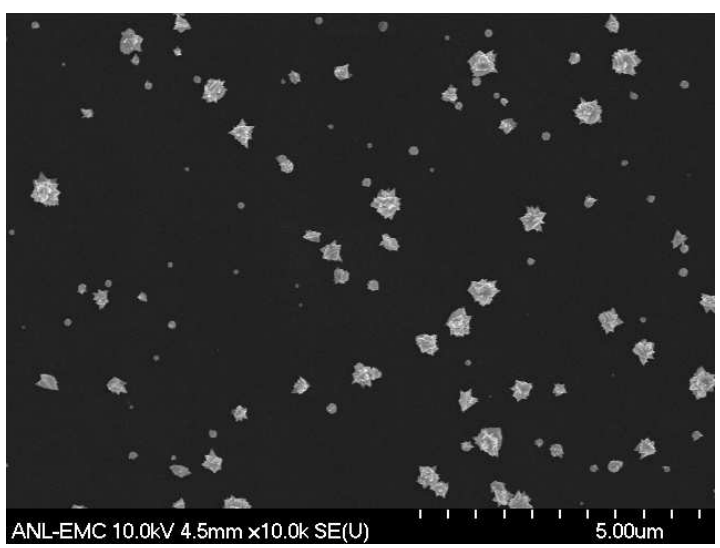

Fig. 3. SEM image of $\mathrm{Pt}_{3} \mathrm{Ni}$ nanoparticles electrodeposited at $-0.300 \mathrm{~V}$ on $\mathrm{HOPG}$.

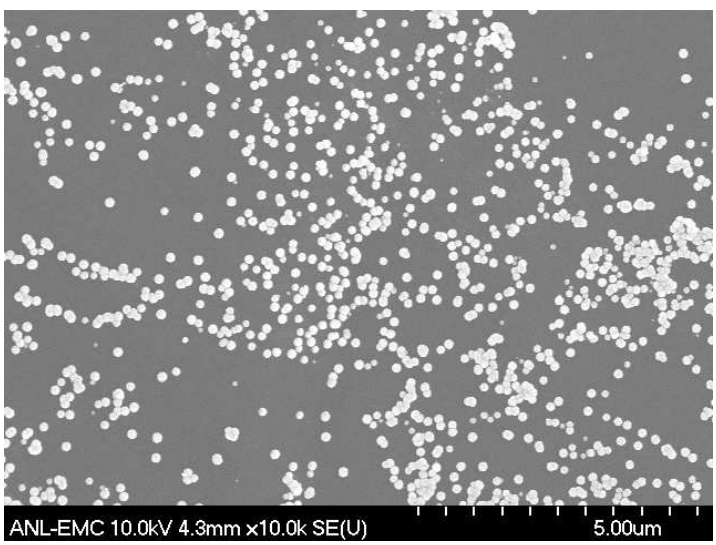

Fig. 4. SEM image of $\mathrm{PtNi}_{3}$ nanoparticles electrodeposited at $-0.600 \mathrm{~V}$ on $\mathrm{HOPG}$.

Although, only about $3 \mu \mathrm{g}$ of the alloy (as estimated from the particle size distribution and density of deposited nanoparticles) is contributing to the total magnetic moment, a clear evidence of dominant magnetic moment of nanoparticles was obtained for $\mathrm{PtNi}_{3}$ sample. The temperature dependence of the magnetic moment of $\mathrm{PtNi}_{3}$ nanoparticles exhibits features of superparamagnetic systems [7]: a difference between ZFC and FC measurements and a round maximum in $\mathrm{ZFC}$ curve. The position of maximum in ZFC magnetic moment was taken as the blocking temperature $T_{B} \approx 225 \mathrm{~K}$. Due to the relatively large average size of nanoparticles $(133 \mathrm{~nm})$ we expect that the resulting magnetic properties cannot be described only by a simple model of single-domain super- 


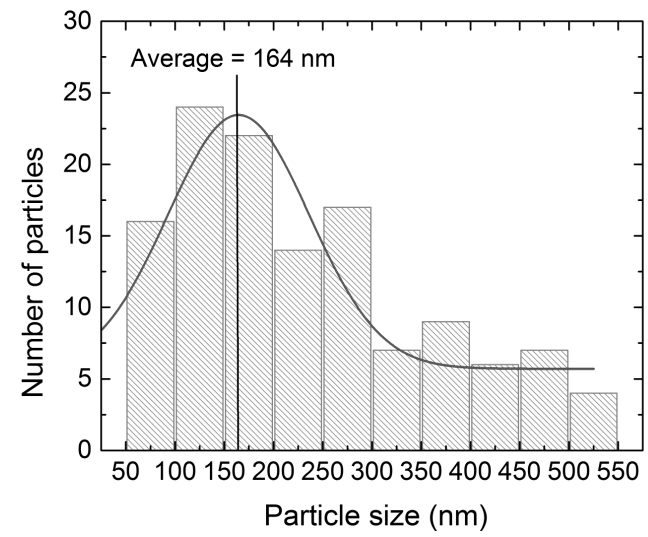

Fig. 5. Histogram of size distribution of $\mathrm{Pt}_{3} \mathrm{Ni}$ nanoparticles on HOPG substrate.

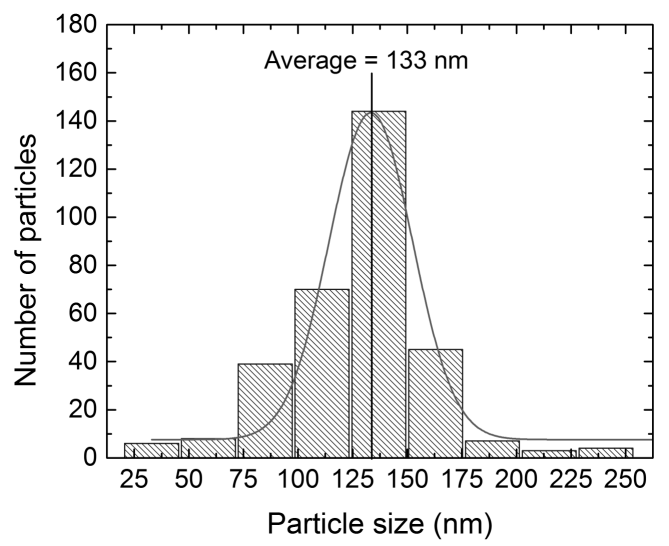

Fig. 6. Histogram of size distribution of $\mathrm{PtNi}_{3}$ nanoparticles on HOPG substrate.

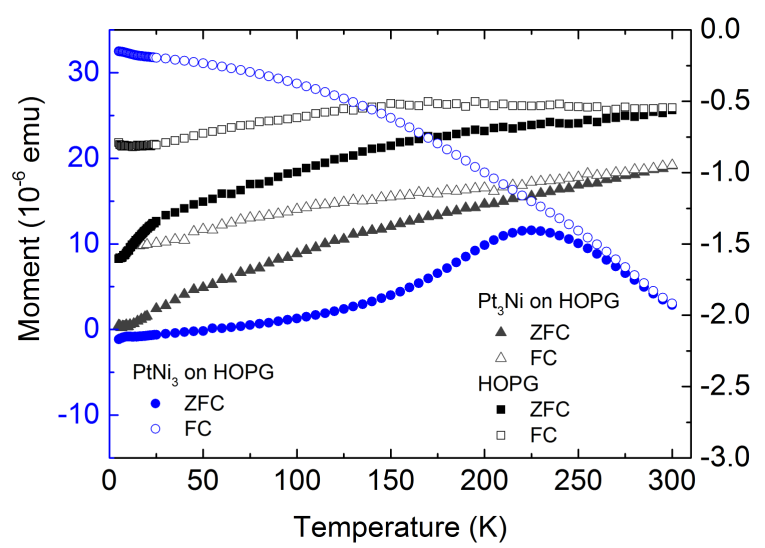

Fig. 7. Temperature dependence of magnetic moment of $\mathrm{Pt}_{3} \mathrm{Ni}$ and $\mathrm{PtNi}_{3}$ nanoparticles on HOPG substrate and pure $\mathrm{HOPG}$ measured in applied magnetic field of 50 Oe. Different scale is used to show the details of $\mathrm{HOPG}$ and $\mathrm{Pt}_{3} \mathrm{Ni}$ nanoparticles magnetic moment. Both ZFC and FC data are measured during the temperature increase. paramagnetic particles (e.g. reported critical size of $\mathrm{Ni}$ nanoparticles is $24 \mathrm{~nm}$ [8]). Also the influence of the substrate on inter-particle interaction needs to be elucidated in further studies [9].

\section{Conclusion}

We have grown $\mathrm{Pt}_{3} \mathrm{Ni}$ and $\mathrm{PtNi}_{3}$ alloy nanoparticles on HOPG using potentiostatic electrodeposition technique. We successfully demonstrated that this technique could be used to produce not only thin films, but also nanoparticles. Composition of nanoparticles could be varied by adjusting the deposition potential. The particle size and their density on surface of HOPG substrates can be controlled by changing the deposition time. The nanoparticles were characterized by SEM and EDS. Electrodeposition allows tuning the size and composition of $\mathrm{Pt}_{100-x} \mathrm{Ni}_{x}$ nanoparticles, which affects their magnetic behavior. Magnetic studies revealed that $\mathrm{Pt}_{3} \mathrm{Ni}$ system is diamagnetic and $\mathrm{PtNi}_{3}$ nanoparticles grown for $100 \mathrm{~s}$ exhibit a superparamagnetic behavior with the blocking temperature $225 \mathrm{~K}$.

\section{Acknowledgments}

This work was supported by the ERDF EU (European Union European Regional Development Fond) grant, under the contract No. ITMS 26220120005, APVV14-0073, APVV-14-0605 and projects VVGS-2014-171, VVGS-PF-2016-72646.

\section{References}

[1] S. Sun, C.B. Murray, D. Weller, L. Folks, A. Moser, Science 287, 1989 (2000).

[2] M.M. Miller, G.A. Prinz, S.F. Cheng, S. Bounnak, Appl. Phys. Lett. 81, 2211 (2002).

[3] V. Franco, K.R. Pirota, V.M. Prida, A. Maia, J.C. Neto, A. Conde, M. Knobel, B. Hernando, M. Vazquez, Phys. Rev. B 77, 104434 (2008).

[4] Y. Liu, C.M. Hangarter, U. Bertocci, T.P. Moffat, J. Phys. Chem. C 116, 7848 (2012).

[5] M.C. Cadeville, J.L. Moran-López, Phys. Rep. 153 , 331 (1987).

[6] D. Spemann, P. Esquinazi, A. Setzer, W. Böhlmann,. AIP Adv. 4, 107142 (2014) and references therein.

[7] D.K. Kim, Y. Zhang, W. Voit, K.V. Rao, M. Muhammed, J. Magn. Magn. Mater. 225, 30 (2001).

[8] R. Das, A. Gupta, D. Kumar, S.H. Oh, S.J. Pennycook, A.F. Hebard, J. Phys. Condens. Matter 20 385213 (2008).

[9] G.A. Badini, V. Vega, A. Ebbing, D. Mishra, P. Szary, V.M. Prida, O. Petracic, H. Zabel, Nanotechnology 22, 285608 (2011). 